\title{
The CEO's Managerial Skills, Ups and Downs of a Firm and Crisis
}

\author{
Alexandru Trifu ${ }^{1, *}$ \\ 1،"Petre Andrei” University, Iasi, Romania \\ *Correspondence: "Petre Andrei” University, Iasi, Romania. E-mail: trifu.alex@ gmail.com
}

Received: October 2, 2017

Accepted: October 24, $2017 \quad$ Online Published: October 28, 2017

doi:10.5430/mos.v4n4p23

URL: https://doi.org/10.5430/mos.v4n4p23

\begin{abstract}
We are dealing in this paper with the general issue of management crisis, crisis as inflection and disturbing point for the economic entity. There many causes for the appearance and ongoing of crisis within socio-economic systems. We chose the most important cause: that of the action and decision-making of the outstanding human resource and propeller for the entire activity, the CEO.

Starting from Peter Drucker's allegation that the CEO is the power-link between the organization and the business/natural environment, we want to highlight that the plans, the ideas, and intentions of a CEO dedicated and efficient lead to efforts and costs inside the entity and results (bad or good) outside, into society and markets. The CEO is main person to see, to predict, the opportunities for the performance of the company. BUT, the results can be favorable on medium run, or only on short run, involving possible subsequent crisis, consisting on undulating movements of the entity activity.

Specifically, we propose the situation of John Reed, former CEO of Citicorp (then Citigroup), in fact the architect of the complex mega-financial structure which became Citigroup and negative repercussions occurred from factual financial activity of the corporation.
\end{abstract}

Keywords: crisis; CEO; skills; experience; financial supermarket; profit; consumers' satisfaction

\section{Crisis Management-an Approach}

The crisis management, by its characteristics and consequences, derogates from the rules set. For example, the crisis is considered as "an event, or set of circumstances, threatening the integrity, the reputation, or the very existence of the individual or organization (....), and the potential losses for the entity are considerable" (Sapriel, 2003).

Barry McLonglin, in a same approach, defines the crisis as being "an event, disclosure, accusation (...) threatening the integrity, reputation and the existence of people and of organization” (McLonglin, 1996).

The field of crisis management is considered starting with famous Johnson \& Johnson situation of 1982, when a cyanide-laced Tylenol killed seven people in the Chicago area. The reaction was prompt, capsules were recalled and the counteroffer was free product in tamper-proof packaging. This quickly swift led to a minimum lose for shareholders and the brand and the production recovered, continued and flourished (Wigmore, 2013).

Imagine the entity, the socio-economic system of it, as human body! And, exactly as in the physiology, they might appear moments of malfunction of different components of the system, pain crisis, negative aspects which might lead to worse the operating system. It is the climax which has to be solved immediately, using different straight and firm actions, in order to restore the proper functioning of the body as a whole.

The same it is the situation within an entity, regarding its management and well-functioning of all components (compartments, divisions, offices). The crisis management can be seen as the application of tactics and strategies designed to help the whole entity (organization) to deal with a sudden and significant negative event occurred (our emphasis).

A crisis occurs, in the quasi-majority of cases, in the ascending curve of the activity and performance of an entity (firm, organization) as a result of an unpredictable event (of endogenous, or exogenous nature), or as a consequence less predictable of an event considered a potential risk (in the risk portfolio of actions and events). 
Patrick Lagadec considers that, sometimes, there are no signs of onset the crisis and there are interim periods which can lead (Chiciudean, Tones, 2002), step by step, to the imminent and disastrous crisis (Lagadec, 1993).

Speaking about crisis in the firm's organism (system), this inflection point in the functioning of the system requires that decisions to be made quickly, by determined and skillful managers (CEOs), in order to limit the damages and perturbations to the firm or organization. A good manager is that one who is prepared to cope with crisis and, more of it, to solve favorably the inconvenient occurred. This situation, because the management and economic practice tell us that the costs are inside the firm (organization, corporation...) and the results (including the feedback process) is on the markets, in communities.

Starting from what Peter Drucker said in 2004 that is the CEO is the link between Inside (organization) and Outside (the economy, society, customers), the CEO is doing for Outside, BUT with the Inside support. The development and sustainable growth (the quantitative aspect of the functioning of a firm) of the institution is the CEO's main responsibility and even legacy (Lafley, 2009).

Furthermore, we can mention (Bertrand and Schoar, 2003) who presented the heterogeneity regarding the CEOs' profiles and abilities, consisting in differences in the level of education, work experience (including the experience in the relationships with staff, employees, people), main traits of character and of personality. Hence, the differences in corporate policies (strategies and tactics) and the performances and value of the corporation (firm, organization)

Therefore, in this paper, we will use the inquiry method, analyzing a management crisis, starting from an entity, a financial one and, mainly, the CEO's activity as core of the human factor of production, who that may influence the status and the future of the corporation. Collecting correct and important data, following the movements on the market and a sense of forecasting, these are the structure elements to determine the possibilities of risks and of an imminent crisis. In many situations however, a crisis had not a catastrophic character.

We focused on a CEO's activity, because this person is the only one to be oriented towards performance and the results of the company (firm, organization), accordingly to the goals of the entity, but also with the standards, regulations and behavior/intentions of stakeholders.

We think that in such cases of crisis, the best practices include, primarily, the existence of programs to be followed (even reserve plans, the well-known plan B...) and procedures to detect early signals of any foreseeable crisis, engaging the team and even stakeholders in these plans.

Also, we may speak about the application of the Murphy Law in this situation, because bad aspects (things) happen, even in the cases when persons like CEOs, for example, have done their best in the interest of the firm, to protect it and the employees.

Integrating the outside and the inside aspects is very hard to do. And the following case demonstrates just that.

* As the methodology, in this paper we took into consideration the analysis of a specific case (event, aspect) and, therefore, by induction to understand the role of a CEO who, using his abilities and skills, to determine the non-linear, but waving operations of the entities, with ups and downs. Also, we used the method of positivism, a philosophy considering that the research on observable and analysis of social economic realities are best for generalization.

Bryman \& Bell (2015), besides positivism (Bryman, 2015), say that inductive method is the best form for qualitative researches, including the highlighting of the managerial behavior and actions within a corporation (firm).

\section{The CEO John Reed and Citigroup}

Our intention is only to outline in few words a prodigious and fruitful activity and performing management of a person, identifiable person with the very CEO. In a word, as John C. Fillmore campaign slogan in presidential elections in U.S.A. 1856 enunciates: the right man for the right place (Currier, 1856).

We start with the best possible assessments about his person and his capability to run the future giant-created, Citigroup. First of all, he is known for the introduction and large-scale banking utilization of ATM (Automatic Teller Machine) and credit cards (instead of cash, checks, or other payment modalities paper-based on). The new modalities of financial operations (at that time) and the opening to the consumers' banking needs, allowed Reed to provide the foundation that made Citicorp one of the world pre-eminent consumer bank.

As CEO at Citicorp, let's say, the first stage of the future financial giant or conglomerate Citigroup, in fact a financial behemoth, John Reed was the person who managed the company very well in troubled times (the 90's of the last century), registered in his normal daily routine the alternation between the inner reflection and the numerous social 
interactions. In this respect, John Reed himself said that from 5 a.m. until 9, 30 or 10 a.m., it's the time for preparing quietly the program for the day (including detailed lists with problems and targets to be reached), and after that, begins the interactions with people from inside and outside the firm. As CEO of a large company, you're also a tribal leader, meaning that people permanently come to talk and advise you (Csikszentmihalyi, 2007).

But, on the other hand, his activity as a CEO, as a skillful and experienced manager is not alike with the term of "workaholic person", which means a compulsory and pathologic work, a forgetfulness of the pleasures and beauty of life. John Reed succeeded to work hard and efficient and to have time for other pleasant activities which contribute to improve the quality of life (Csikszentmihalyi, 2007).

He was considered a remarkable person, with many skills and abilities in the field, no hands-on manager for many years of the effective leadership as a CEO, but with negative aspects consisting in changing over the years of the senior managers and, by compensation, an inability to trust and work efficiently with his staff (O’Brien, 1998).

In the analyzed case, we cope with crisis of skewed management values, we are saying so, from the classification of management crisis, because the direction to be followed was the enlargement and enrichment, the appetence of what the CEO lusted in his vision of becoming, neglecting ongoing the stakeholders and broader social values. And, in the following stages of functioning and existence of the corporation, it was noted the trend to disregard the interests of other categories of stakeholders such as clients, employees and community.

In any event occurred, John Reed succeeded to survive the uncertainty of the early 90 's (a first major descending curve, wave) and, much more, sustained and repositioned Citicorp for at least 6-7 years to become one of the most profitable and reliable bank of the world, and for real, in couple of decades, the most international of US banks.

And, another strength point for John Reed is the Machiavellian leader skills (face to production and toward obtaining profit and power), because he lacked in the social acumen and in the work with collaborators and own executives.

As a partial conclusion, in order to understand the actions and the facts of John Reed and of Citicorp, later Citigroup, we may say that he was a very skillful and determined top manager, using his brain and extensive knowledge, both in the financial domain and in general culture to give more power to his entity, to enrich it (and himself) and to prove his managerial ability to run a business on a large scale. "He is a very remarkable person, but by the standards of you and me he lives on another planet", said a former senior executive of Citicorp in this respect.

All in all, John Reed remains as a brash, very chancy, very vintage manager of his time (O’Brien, 1998). He intended to proof his capabilities, his knowledge, maybe in a race of his own, in order to gain, including the entity who was leading, neglecting medium to long run evolution.

\section{Managing Crisis Resolution}

In the presence of this huge entity of financial nature and structure, the problems emerged from the interior, from the actions and decisions-made by the CEO. We are not, in this case, in the presence of direct impact of products on people or environment (see the famous cases Tylenol or Exxon), but in the situation of a financial organism which grew and enlarged its dimensions, even by merger and including different complementary financial institutions in its composition (Davis). The merger with Travelers Group Inc. was the wrong action and the starting point for the descending curve (the involution) in the functioning of Citigroup, a very daring venture. This merger, the biggest transaction in the history, until the end of 20th century, for a sum of $\$ 70$ billion dollars and was the success of the audacious plan thoroughly thought by John Reed.

Later, John Reed affirmed that putting together Citi and Travelers we created (him and Weill) a monster. And, of course, we agree with Reed, that the most difficulties were occurred (met) from the Salomon Brothers side" (Martens, 2015), a very important and inconvenient player on the market. One of the a priori most important issues foreseen by the CEOs was the bringing together of two different organizational cultures, not entirely incompatible, but regarding two complementary and distinctive financial activities.

Sanford "Sandy" Weill ("the bad boy" CEO of Travelers and Reed have developed financial ingenious schemes for the development of the new entity, but for the most part, in their own profit. The result, the near one, was the making out of shareholders and the enriching of them: primarily for Weill, but also for Reed (for example, in the A.D. 1997, Reed owned stock and options, currently valued at minimum $\$ 272$. mil. of dollars).

In sum, Weill was principal right in one aspect: both he and Reed became "so rich", even the company was in decline. Primarily, by merging with Travelers, the new established corporation, the Citigroup, tried to offer for their consumers' 
satisfaction all over the world, banking, mutual funds, brokerage insurance services under the same roof, in one giant financial unit.

The Citigroup, so accomplished, is based on a model of a "financial supermarket", with one single stop for customers to solve all financial issues.

Citigroup was considered, at the beginning of the Millennium (and after the John Reed departure and his 4.7 million shares selling), the weakest of the of the big-five Wall Street institutions but its strengthening earnings and sale of non-core assets allowed it to become the first to report a double-digit capital ratio under the new Basel III standards.

The artisan of the later strengthening and favorable situation of Citigroup is considered Mike Corbat, who led this huge entity, in 2007, in its best half-year earnings for 6 (six) years (Braithwaite, 2013). But, over the period 2000-2011, the general aspect regarding the earnings of shareholders has shown a drastic decrease (almost a decimation of value) $\mathrm{cu}$ 88\% in 2011 compared to 2000 (April 18, when John Reed stepped down, with 100 shares valuing \$6,212-by comparison, in 2011, the same 100 shares worth \$729.82).

The selling of a large amount of shares $\$ 4.7 \mathrm{bn}$, after 2010, has represented another good financial shot in order to increase the performance of Citigroup, in what Mike Corbat said that is "the largest percentage reduction of assets since 2010" (Braithwaite, 2013).

Another up and down occurred in 2008, in fact a crash during the Great Depression during the first decade of the new Millennium and again John Reed was in the middle of Citigroup media impact, admitting, once again, that the creation of this mega financial structure which is Citigroup was a bold, but terrible idea, in what its "creator" compared the entity, as we saw, with a financial supermarket (all components, "stores", being from the same domain).

Much later (2010 for precision), not only John Reed recognized that he created a "monster" by Citigroup merger, but also media define him as being dead wrong in the drawing of this financial mega-entity (Martens, 2015).

An aspect which has to be brought in attention is the relationship between this mega financial entity and State regulations. More precisely, we speak about John Reed's managerial success in breaking down the Glass-Steagall Act (in force from the Great Depression 1929-1933). It was no collusion between Government and Corporate entity in this case, the removal of the Glass-Steagall Act facilitating the merger between the two mentioned corporations. Furthermore, Bill Moyers highlighted that the merger Citicorp and Travelers, from one side and a so-called Presidential pen, on the other hand, brought down the above mentioned Act, considered a firewall between banks and investment firms which had protected consumers from financial losses. On his turn, John Reed, several years earlier, evoked the protectionist character of the Act, if not in its intent, but in its consequences and since then, he sprouted the idea of removal this regulation for personal benefit (for him and his firm). The Clinton Administration, exactly by President's pen, obligingly repealed the Glass-Steagall Act one year after the above-mentioned merger.

\section{Results}

From all written sources consulted, including the own opinions of the involved CEOs in the problem (much more of John Reed's), it is clear that the premonitions, based on knowledge, skills, business flair, in respect of John Reed, were confirmed in the last decade of $20^{\text {th }}$ century, in that represented by financial organizations, having as core a commercial bank, which are capable to integrate investment banks, insurance company, will dominate the global market at the beginning of $21^{\text {st }}$ century, making the leap from a so-called balkanized system (referring to USA in the early 90 's) to post-modern and futurist financial entity.

The inquiry showed us the importance of a CEO's actions, his will and administrative good organization of the work, towards reaching a better place on the specific market and to survive, by continuing its activity and designation.

In fact, the feature that we intended to emphasize was that of CEO tenure on medium run for one person and, by consequence, the evolution of the activity of the respective entity, and possible avatars in its existence and functioning.

More of that, the model of John Reed, in its main features, was appropriated by other manager and CEOs. And this aspect appeared due to the fact that, as we know, the financial (capital) market is the most sensitive and risky market and it was necessary to find people with the required skills and know-how to manage the difficulties of the firms.

Due to the fact that the life cycle of a firm, corporation, follows exactly the curve of the business cycle, we think that, in this specific case, we are not in the presence of $\mathrm{U}$-shape evolutionary curve.

We have reached to the results of a CEO's activity and of his appointment through empirical studies and observations (Limbach, P. et al., 2015) including in this category, for example, the downfall of a private university to the medium 
run mismanagement of its rulers (i.e., do not count the existence and goal of the entity, important was the welfare and prosperity of rulers).

\section{Conclusions}

Each organizational activity, we may say that, is unique. Therefore, it is quite impossible to offer general solutions and even scenarios for managing crisis, only general directions, plans and measures, in order to flat the crisis' impact and recover, in good parameters, the entity activity. The situation is not quite black or white. To deal with the crisis can be learned from books, papers, courses, but merely taking into account the abilities to notice and understand the details, intuition, of the managers, or of the team called to solve the situation.

In our case, we are dealing with the activity and decision-making process of the most important human resource of a corporate entity: the CEO and outstanding stakeholder at the same time. The decisions taken by the CEO of the Citicorp, then of the Citigroup and ultimately of the conglomerate including by merger Travelers were in accordance with the excellent expertise of him, the capacity to understand the mechanisms and actions from the financial markets and, at the same time, with his desire to enlarge the power of the corporation.

For real, John Reed in his developing and ascending period was a "prince" of the Wall Street, but the deal with Travelers was the fine action in order to impose the supremacy, a forward thinking, in terms of banking production and geographic strategy (a very break-out and audacious goals planned, correctly executed the merger and the entire financial re-positioning in the financial services industry, as warned in due time, Judah Kraushaar from Merrill Lynch).

It is the situation in which, human intuition, experience, skills, are responsible both for triggering crisis (financial, in our study), but also for the measures taken, along some future periods of time, in order to reduce and eliminate the crisis effects. These traits are necessary, both for corporation and for clients/business environment.

The organization is capable, by itself, both through internal mechanisms (see the capabilities and skills of CEOs and other top managers or leaders) and external (the signals from the feedback process on the specific market) to respond, on short term, or medium to long term (as this case is) to crisis that may occur in its work and functioning. In fact, the agitated history of Citigroup, with scandals, bailouts, important losses for its shareholders, was a permanent challenge (a permanent source of crisis, we may say) for all parties involved in the field (supporters or opponents of the virtues of a global banking system).

The strategy high risk, the bringing together of several financial institutions in one huge unit, was the main cause of the collapse of Citigroup, BUT the tactics imposed and followed by audacious CEOs led to a temporary recovery of the activity, ensuring that undulation of the functioning that I have mentioned (prosperous periods-good management, disastrous periods-poor management, like that of Chuck Prince).

In the case described above, we had to deal with a corporation (an entity) which survived decades of existence, having as CEOs professional and dedicated persons in the financial field. Hence, its cyclical activity, each time, in the difficult times (of crisis), suitable managers appeared, at the proper time and place, in order to save the organization and to continue to be in the benefit of communities. Of course, it should be not forgotten the regulatory action of the State, either in the respect of a new Act Glass-Steagall type, or even the removal of Government subsidies, still operating by the financial hyper-units.

The final idea is that regarding the period of ups and downs in the firm's life cycle, especially downs and on medium-term, trend leading in many cases to insolvency and in other cases, uniting endogenous with exogenous factors, the respective entity is recovering and records increases.

\section{References}

Bertrand, M., \& Schoar, A. (2003). Managing with style: The effect of managers on firm policies. Quarterly Journal of Economics, 118, 1169-1208. https://doi.org/10.1162/003355303322552775

Braithwaite, Tom. (2013). Citigroup recovery under Mike Corbat, boosted by strong trading, in Financial Times. Retrieved August 30, 2017 from www.ft.com/content

Bryman, A. (2015). Social research methods. Oxford University Press.

Bryman, A., \& Bell, E. (2015). Business research methods. Oxford University Press. 
Chiciudean, Ion \& Țoneş, Valeriu (2002). Gestionarea crizelor de imagine (The image crisis management). Comunicare.ro, Bucharest.

Csikszentmihalyi, Mihalyi. (2007). Starea de flux (Findings Flow. The Psychology of Engagement of Everyday Life). Curtea Veche Publishers, Bucharest.

Currier, Nathaniel. (1856). The right man for the right place, lithography. Retrieved September 3, 2017 from www.loc.gov/pictures

Davis, Marc-Crisis Management Strategies for Business Owners. Retrieved September 2, 2017 from www.investopedia.com/articles/financial-theory

Lafley, A. G. (2009). What only the CEO can do. Harvard Business Review. Retrieved November 28, 2016 from www.hbr.org/2009

Lagadec, Patrick. (1993). Preventing Chaos in a Crisis-Stretegies for Prevention, Control and Damage Limitation (English version). McGraw-Hill Book Company, London.

Langley, Monica. (2003). Tearing Down the Walls: How Sandy Weill Fought His Way to the Top of the Financial World..., Wall Street Journal Books.

Limbach, Peter et al. (2015). Do CEOs Matter? Corporate Performance and CEO Life Cycle. Swiss Institute of Banking and Finance, School of Finance Working Papers, p. 1-6.

Martens, Pam \& Russ. (2015). John Reed: How to be Dead Wrong as a CEO and Still Get Super Rich, Retrieved September 7, 2017 from www.wallstreetonparade.com/2015

McLonglin, Barry. (1996). Risks and Crisis Communication. McLonglin Multimedia Publishing Ltd., Ottawa, Canada.

Nudell, Mayer. (1998). The Handbook for Effective Emergency and Crisis Management. Lexington, Massachussetts, Lexington Books.

O'Brien, Timothy L. (1998). Prince of the Citi: Reed Runs Citicorp with Brains and Pragmatic Skills. Retrieved September 9, 2017 from www.nytimes.com/1998

Sapriel, Caroline. (2003). Effective crisis management: tools, and best practice for the new millennium. Journal of Communication Management, 7(4). https://doi.org/10.1108/13632540310807485

Wigmore, Ivy. (2013). What is Crisis Management? Retrieved September 13, 2017 from www.whatistechterget.com/definition/crisis-management

Wilmarth, Arthur E., Jr. (2014). Citigroup: A Case Study in Managerial and Regulatory Failures. Indiana Law Review, 47, 69-137. 